\title{
Differential Regulation of $\gamma$-Aminobutyric Acid Receptor Channels by Diazepam and Phenobarbital
}

\author{
Roy E. Twyman, MD, Carl J. Rogers, PhD, and Robert L. Macdonald, MD, PhD
}

The anticonvulsant activity of diazepam and phenobarbital may be mediated in part by enhancement of inhibition involving $\gamma$-aminobutyric acid (GABA). While both diazepam and phenobarbital increase GABA receptor chloride current, they may have different mechanisms of action, since they bind to different sites on the GABA receptorchloride channel complex. We used the patch clamp technique to compare the effects of diazepam and phenobarbital on single GABA receptor currents. Outside-out patches were obtained from mouse spinal cord neurons grown in cell culture for 2 to 4 weeks. GABA $(2 \mu \mathrm{M})$ evoked single channel currents that occurred as single brief openings or in bursts of multiple openings. Diazepam ( $20 \mathrm{nM}$ ) and phenobarbital (500 $\mu \mathrm{M})$ both increased the GABA receptor current by increasing mean open time without altering channel opening frequency. However, the temporal grouping of openings into bursts suggested that the enhancement occurred via different mechanisms. Diazepam increased the frequency of bursting GABA receptor currents with minimal effect on the duration of bursts. Phenobarbital increased the duration of bursting GABA receptor currents without altering the frequency of bursts. These results suggest that diazepam binds to a site that may enhance single channel burst frequency by increasing the affinity of GABA binding, while phenobarbital may stabilize the bursting open state of the channel by binding to a different modulatory site at or near the chloride channel.

Twyman RE, Rogers CJ, Macdonald RL. Differential regulation of $\gamma$-aminobutyric acid receptor channels by diazepam and phenobarbital. Ann Neurol 1989;25:213-220

Benzodiazepine and barbiturate drugs are used clinically for their anticonvulsant, anesthetic, anxiolytic, and sedative-hypnotic effects [1]. The anticonvulsant activity of these structurally distinct classes of drugs may, in part, be mediated by potentiating $\gamma$-aminobutyric acid (GABA)-mediated inhibition of neuronal excitability [2-5]. The postsynaptic $\mathrm{GABA}_{\mathrm{A}}$ receptor complex contains a chloride channel as well as binding sites for GABA. In addition, the receptor contains specific binding sites for benzodiazepines and barbiturates [4]. The GABA receptor is structurally composed of two polypeptide subunits, $\alpha$ and $\beta$ chains, with a subunit structure of $\alpha_{2} \beta_{2}$. The benzodiazepine binding site is located on the $\alpha$ chain, while the GABA binding site is located on the $\beta$ chain [6]. It is unclear where the barbiturate binding site is located. The benzodiazepine diazepam (DZ) binds at the benzodiazepine binding site and enhances binding of GABA. The barbiturate phenobarbital $(\mathrm{PhB})$ binds at or near the chloride channel but does not significantly affect binding of GABA [5, 7]. The physiological consequence, however, of the different binding sites for these two anticonvulsant drugs is unclear.

GABA binds to its receptor and gates open the chloride channel, producing an inward chloride ion flux and membrane hyperpolarization. Benzodiazepines and barbiturates increase and/or prolong GABA receptor current, but the mechanisms of drug modulation of coupling between neurotransmitter binding and chloride channel gating are poorly understood. Characterization of drug effects on channel gating has not been possible with intracellular and noise analysis techniques. Recent development of the patch clamp technique, however, has enabled direct recording of neurotransmitter-gated single channel currents [8]. Patch clamp studies of the nicotinic acetylcholine $(\mathrm{ACh})$ receptor complex have revealed that binding of $\mathrm{ACh}$ increases the likelihood that the ACh receptor channel will open in bursts or groups of openings separated by relatively long closed periods [9]. Direct recording of channel openings and closings allows statistical inferences to be made about the properties of neurotrans-
From the Department of Neurology, University of Michigan Medical Center, Ann Arbor, MI.

Received Mar 3, 1988, and in revised form Aug 18. Accepted for publication Aug 20, 1988.
Address correspondence to Dr. Macdonald, Neuroscience Laboratory Building, 1103 East Huron Street, Ann Arbor, MI 481041687. 
mitter-gated channels and modification of that gating by drugs. Thus, it is now possible to study directly the coupling between neurotransmitter binding and channel gating and the actions of modulatory drugs on the channel gating process.

We have used the patch clamp technique to investigate the actions of $\mathrm{DZ}$ and $\mathrm{PhB}$ on single GABA receptor chloride currents from mouse spinal cord neurons grown in dissociated cell culture [10-12]. GABA responses of mouse spinal cord neurons have been shown to be enhanced by benzodiazepines and barbiturates and antagonized by the GABA antagonists picrotoxin and bicuculline [13]. In this study we have shown that $\mathrm{DZ}$ and $\mathrm{PhB}$ enhance GABA receptor single channel chloride currents by different mechanisms. These results provide evidence at the molecular level for different modes of action for the regulation of GABA receptor channels by benzodiazepines and barbiturates, which suggest that the modulatory sites for these drugs at the GABA receptor are different.

\section{Methods}

Cultures were prepared from spinal cords obtained from 12to 14-day-old fetal mice as previously described $[3,10]$. Briefly, a single-cell suspension obtained after mechanical dissociation and trypsinization was plated on collagen-coated dishes at a density of $10^{6}$ cells $/ \mathrm{ml}$ in a growth medium containing $80 \%$ minimal essential medium, $10 \%$ fetal calf serum, and $10 \%$ heat-inactivated horse serum. Following 3.5 days of incubation, uridine $(35 \mathrm{\mu g} / \mathrm{ml})$ and $5^{\prime}$-fluorodeoxyuridine $(15 \mu \mathrm{g} / \mathrm{ml})$ were added to suppress growth of rapidly growing nonneuronal cells and the medium was changed to $90 \%$ minimal essential medium and $10 \%$ heat-inactivated horse serum. Cultures were maintained for 2 to 4 weeks prior to use.

At the time of recording, culture medium was exchanged for a physiological salt solution (in mM: $142 \mathrm{NaCl}, 8.09 \mathrm{KCl}$, $1 \mathrm{CaCl}_{2}, 6 \mathrm{MgCl}_{2}, 10$ glucose, $10 \mathrm{Na-HEPES}$ [pH 7.4]) containing strychnine $(200 \mathrm{nM}$, Sigma Chemical Co, St Louis, $\mathrm{MO})$, a specific glycine antagonist. Tetrodotoxin $(1 \mu \mathrm{M}$, Sigma Chemical $\mathrm{Co}$ ) was added to the solutions in the whole cell recordings to suppress spontaneous activity. Recording patch clamp pipettes were filled with a salt solution (in mM: $153 \mathrm{KCl}, 1 \mathrm{MgCl}_{2}, 10 \mathrm{Na}$-HEPES, 5 ethylene bis(oxyethylenenitrilo)tetraacetic acid, $1 \mathrm{NaOH}, 1 \mathrm{KOH}[\mathrm{pH} 7.38])$ to provide a symmetrical chloride concentration (chloride equilibrium potential $0 \mathrm{mV}$ ).

A local pressure ejection technique was used to apply GABA (Sigma Chemical $\mathrm{Co}$ ) and the drugs to the neurons or excised outside-out patches. GABA alone or with $D Z$ or $\mathrm{PhB}$ was dissolved in bath solution at the desired concentration and used to fill a blunt-tipped micropipette. To apply test solutions, a tight-fitting polyethylene tube was fitted over the open end of the pipette and connected to a regulated pressure source. GABA $(2 \mu \mathrm{M})$ was applied by pressure ejection for 20 to 30 seconds. GABA $(2 \mu \mathrm{M})$ and DZ (20 nM, Hoffmann-LaRoche, Nutley, NJ) or GABA and PhB
( $500 \mu \mathrm{M}$, Sigma Chemical Co) were applied by pressure ejection, and $\mathrm{DZ}(20 \mathrm{nM})$ and $\mathrm{PhB}(500 \mu \mathrm{M})$ were either pressure applied or added to the bath prior to exposure to GABA plus anticonvulsant. Pressure was applied to ejection pipettes for 5 to 10 seconds when the pipettes were distant from the cell or patch to ensure that no dilution of drug had occurred at the pipette tip. The tips of the pressure ejection pipettes were then brought to within $50 \mu \mathrm{m}$ of the neuron or patch for application and were removed immediately from the bath solution after drug application.

Whole cell and patch clamp recording techniques [8] were similar to those of Hamill and colleagues [15]. Neurons or membrane patches were voltage clamped at the potassium equilibrium potential $(-75 \mathrm{mV})$. Recordings were obtained using an L/M EPC-7 patch clamp amplifier (List Medical Instruments, Darmstadt, West Germany) and recorded on a video data recording system for later analysis. Single-channel data were digitized at $8 \mathrm{kHz}$ with a $1-\mathrm{kHz}$ eight-pole Bessel filter interposed. Channel openings and closings of the main conductance state (27-30 picosiemens [pS]) were detected using a 50\% threshold crossing criterion [8] and analyzed using programs written in this laboratory. Only patches with stable responses and infrequent multiple simultaneous channel openings were used for analysis. Those rare multiple openings detected by the program were classified as closures. Events less than twice the dead time of the system (dead time $=130 \mu \mathrm{sec}$ ) were rejected from analysis.

Since channels open and close randomly with a characteristic probability, several thousand events must be obtained to evaluate their probabilistic (nongaussian) distribution. However, to compare the effects of drugs on the GABA receptor channel openings, data were analyzed by calculating the mean open, closed, and burst durations (defined below) per GABA application and evaluating the results by one-tailed Student's $t$ test for independent groups. Data were presented in the form of mean \pm standard error unless otherwise specified. To display frequency distributions, open and closed durations were pooled from several recordings and collated into frequency histograms of variable binwidths.

\section{Results}

Whole-cell inward chloride currents exhibited typical GABA pharmacological characteristics and were blocked by picrotoxin and bicuculline (not illustrated). Whole-cell recordings were used to establish DZ and $\mathrm{PhB}$ concentrations that produced similar enhancement of GABA receptor currents. GABA evoked inward current with an associated increase in membrane conductance (Fig 1A1, B1). Both $\mathrm{DZ}$ and $\mathrm{PhB}$ produced about a twofold increase in the GABA receptor current (Fig 1A2, B2). The enhancement of GABA receptor current was reversible (not illustrated).

Single channel chloride currents exhibited typical GABA pharmacological characteristics and were blocked by picrotoxin and bicuculline (not illustrated). Excised outside-out patches that demonstrated GABAsensitive channel openings typically had rare, brief spontaneous openings (Fig 2A). GABA (2 $\mu \mathrm{M}$ ) evoked predominantly bursting currents (Fig $2 \mathrm{~B}$ ) in 


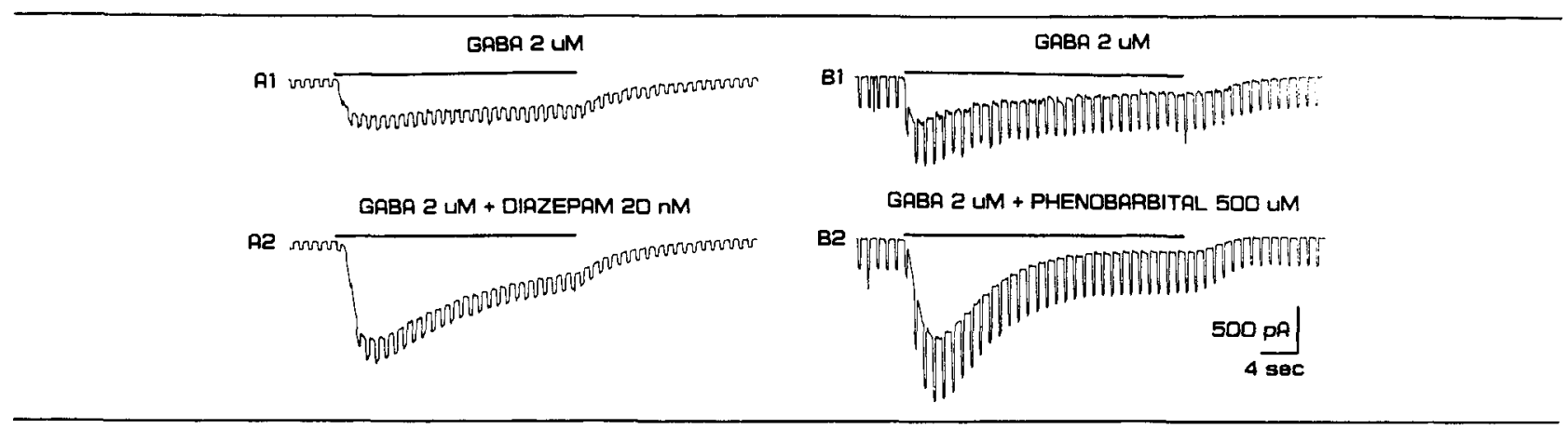

Fig 1. $\gamma$-Aminobutyric acid (GABA) receptor cbloride currents were entanced by diazepam $(D Z)$ and phenobarbital $(P b B)$. $G A B A$ receptor current $(A 1)$ was enbanced when $D Z$ was applied with $G A B A$ (A2). $G A B A$ receptor current (B1) was also enbanced when applied with $P b B(B 2)$. Application of $G A B A$ or $G A B A$ and drug is indicated by a solid line. The enbancement of $G A B A$ receptor current was associated with an increase in the conductance change produced by GABA. Short-duration byperpolarizing voltage commands (100 msec) were applied prior to and during application of GABA. The amplitudes of the currents required to achieve those voltage commands are sbown in the traces. The amplitudes of these currents were proportional to membrane conductance. With GABA application, the amplitude of the sbort currents increased, indicating an increase in membrane conductance. Following $D Z$ or $P b B$ application, the $G A B A-$ induced increase in pulsed currents was enbanced. Thus, GABA increased membrane conductance by opening chloride channels, and $D Z$ and $P h B$ augmented that enbancement in membrane conductance.

$80 \%$ of patches. Openings with at least two different current amplitudes were recorded, representing two different conductance states (not illustrated). The larger conductance state (approximately 26-30 pS) occurred much more frequently and was used in these analyses. $\mathrm{DZ}(20 \mathrm{nM})$ and $\mathrm{PhB}(500 \mu \mathrm{M})$ both increased single channel activity evoked by GABA (Fig 2C,D). Channel conductance in the presence of $\mathrm{DZ}$ and $\mathrm{PhB}$ was unchanged. A drug may increase ion flux through a channel by independent or combined increases in channel conductance, open duration, or opening frequency. Since neither $\mathrm{DZ}$ nor $\mathrm{PhB}$ altered conductance, we determined the opening and closing temporal characteristics of the channel.

Multiple single-channel recordings of GABA receptor single channel currents were summed to produce an average current per recording. The time course of the summed single channel GABA receptor current (Fig 3A) was similar to the GABA-evoked whole cell current (see Fig 1). Both $\mathrm{DZ}$ and $\mathrm{PhB}$ enhanced the summed single channel GABA receptor currents (Fig $3 B, C)$. For both anticonvulsants, the enhanced, summed currents had a time course similar to that for the whole cell currents (see Fig 1). In the early portions of the summed and whole cell currents, current increased. This was likely due to the lag time before

the concentration of GABA from the ejection pipette became maximal and constant. In the presence of $\mathrm{DZ}$ and $\mathrm{PhB}$, the current tended to decline over time, possibly because of desensitization. However, the currents were relatively stable after the initial rising period and prior to the late decline of current. For analysis of the temporal characteristics of the current, it was important that the current was stable or stationary. Therefore, for kinetic analysis of single channel gating characteristics, currents were analyzed from 2 to 17 seconds after the first channel opening.

Both $\mathrm{DZ}$ and $\mathrm{PhB}$ altered the mean open properties of GABA receptor single channel currents (Table). Mean open time per application of GABA was 5.0 msec (158 applications). DZ increased the mean open time to $7.3 \mathrm{msec}$ ( $p<0.0005,22$ applications). $\mathrm{PhB}$ also increased the mean open time to $5.7 \mathrm{msec}(p<$ 0.05, 54 applications). Per application, GABA evoked a mean of 13.4 openings/sec. Neither DZ (12.9 openings/sec, not significant [NS]) nor $\mathrm{PhB}$ (15.5 openings/ sec, NS) altered the number of GABA receptor openings per second. With GABA applied alone, the channel was open $6.2 \%$ of analysis time. Following the addition of $\mathrm{DZ}$ or $\mathrm{PhB}$, the channel was open $8.9 \%$ ( $p$ $<0.05)$ and $8.4 \%(p<0.0025)$ of analysis time, respectively. Thus, DZ increased the mean open duration for each channel opening but did not increase the frequency of opening. Although $\mathrm{PhB}$ was less effective in increasing mean open duration, the slight increase in GABA receptor channel opening frequency accounted for approximately the same total increase in ion flux.

To visualize how $\mathrm{DZ}$ or $\mathrm{PhB}$ increased the mean open duration, channel open or closed durations may be displayed in the form of histograms showing the relative frequency of occurrence of an opening or closing with a particular duration. In general, the longer an opening or closing, the less frequently it was observed. Frequency distribution histograms were obtained and normalized to display the effects of the drugs on the distributions. Visual inspection of normalized open duration frequency histograms showed that in the presence of $\mathrm{DZ}$ or $\mathrm{PhB}$, mean channel open time was 


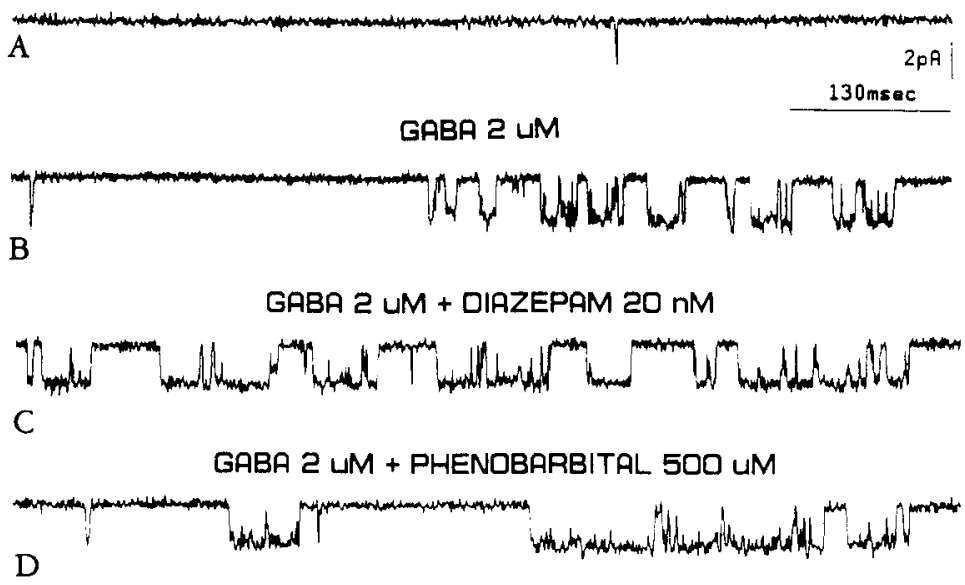

Fig 2. Single channel chloride current evoked by $\gamma$-aminobutyric acid (GABA) was enhanced by diazepam (DZ) and phenobarbital $(P b B)$. (A) Prior to application of $G A B A$, only rare brief spontaneous currents were present. (B) Following application of $G A B A$, channel openings increased in frequency and occurred as individual openings or in groups of openings (bursts). (C) In the presence of $D Z, G A B A$ produced increased channel activity. (D) In the presence of $P b B, G A B A$ again increased $G A B A$ receptor channel activity. Membrane patches were voltage clamped at the potassium equilibrium potential ( $-75 \mathrm{mV}$ ). Downward deflections in all tracings represent channel openings and inward chloride currents.

increased (Fig 4). DZ shifted the distribution of openings to longer durations but appeared to have a greater effect on increasing the relative proportion of long openings. The effect of $\mathrm{PhB}$ was a shift of the distribution of all openings to longer durations. In particular, $\mathrm{PhB}$ had a greater effect than $\mathrm{DZ}$ had on the distribution of short openings. The effect of $\mathrm{DZ}$ on the relative proportion of long openings was also apparent in that the mean open time for $\mathrm{DZ}$ was longer than that for $\mathrm{PhB}$. Although closed times varied over a wide range (from microseconds to seconds), the distributions of closed time less than $50 \mathrm{msec}$ were altered little by $\mathrm{DZ}$ or PhB (Fig 5).

The general properties of mean open duration and opening frequency do not provide information about how openings may be clustered or grouped together. $A$ burst can be defined as a group of openings separated by a relatively long closure [8]. As previously mentioned, both GABA and ACh evoke bursts of channel openings, suggesting that bursting activity may be a fundamental behavior of bound receptor-gated ion channels. The bulk of the ion flux through the channel occurs during a burst containing several openings, whereas isolated, brief channel openings pass relatively little current. To examine burst characteristics in this analysis, only those events longer than $10 \mathrm{msec}$ were evaluated. Thus, a series of openings and closings

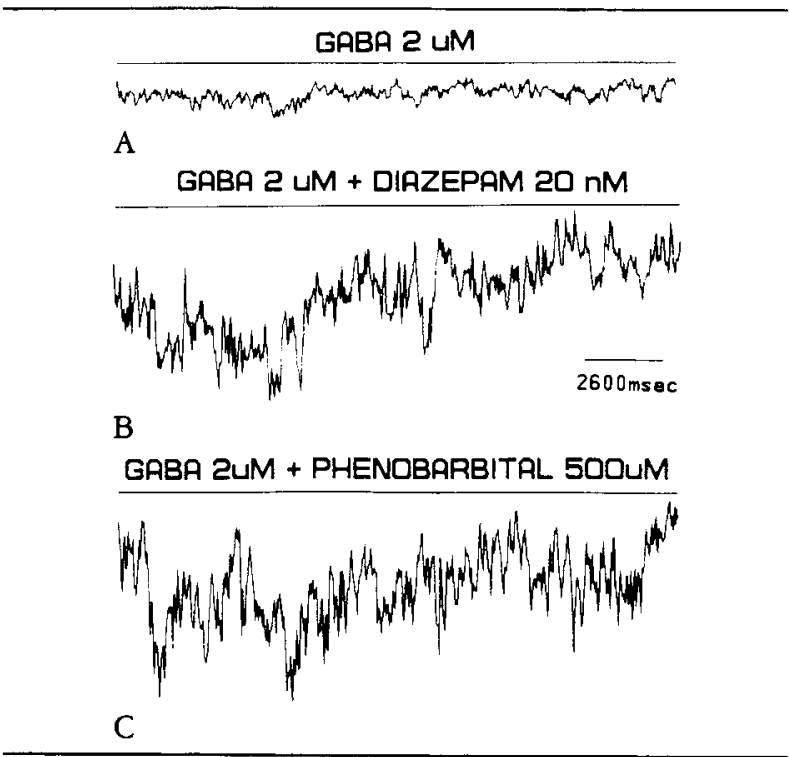

Fig 3. Diazepam (DZ) and phenobarbital (PbB) increased $\gamma$ aminobutyric acid (GABA) receptor current. (A) GABA was applied to 115 patches to evoke inward single channel currents. The currents from these patches were added and resulted in a summed inward current. This summed inward current had a time course similar to that of the inward currents produced by $G A B A$ using whole cell recording. (B) Single channel recordings from 22 patches in the presence of $G A B A$ and $D Z$ were added to produce a summed single cbannel current. The current was normalized for the number of patches for comparison to $A$. (C) Multiple recordings of single channels from 54 patches in the presence of $G A B A$ and $P b B$ were added to produce a summed current. The summed current was then normalized to the number of patches for an ensemble average current for comparison to $A$. In all cases, each application of $G A B A$ was added from the beginning of the first opening. Multiple simultaneous channel openings were not rejected so that total charge transfer per application could be added. These summed traces demonstrate that $D Z$ and $P b B$ enbanced the total amount of current passed per application of $G A B A$. 


\begin{tabular}{lccc}
\hline & GABA & GABA + Diazepam & GABA + Phenobarbital \\
\hline Mean open time (msec) & $5.0 \pm 0.2$ & $7.3 \pm 0.6^{* * *}$ & $5.7 \pm 0.4^{* * *}$ \\
Openings per second & $13.4 \pm 1.0$ & $12.9 \pm 1.9$ & $15.5 \pm 2.1$ \\
Percent time channel open ${ }^{\mathrm{b}}$ & $6.2 \pm 0.5$ & $8.9 \pm 1.5^{* *}$ & $8.4 \pm 1.1^{*}$ \\
Total number of openings & 28,872 & 4,051 & 10,400 \\
Number of drug applications & 158 & 22 & 54 \\
\hline
\end{tabular}

${ }^{a}$ To maintain stationary channel kinetics, single channel records were analyzed from 2 to 17 seconds after GABA or GABA plus drug application. Data are presented in the form of mean \pm standard error per application of drug. GABA, diazepam, and phenobarbital concentrations were $2 \mu \mathrm{M}, 20 \mathrm{nM}$, and $500 \mu \mathrm{M}$, respectively.

${ }^{b}$ The percentage of time in the recording from 2 to 17 seconds that the channel was in the open state.

$* p<0.05$.

$* * p<0.005$.

$* * * p<0.0005$.

$\mathrm{GABA}=\gamma$-aminobutyric acid.

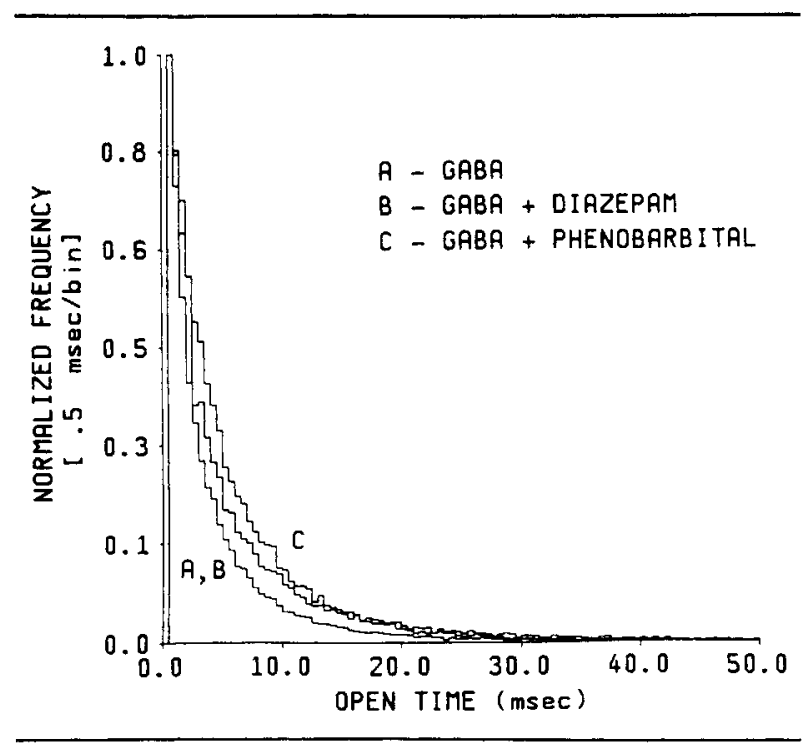

Fig 4. Normalized channel open time frequency bistogram. Frequency bistograms display the relative occurrence of an opening or closing of a particular duration. In general, a long duration event occurred less frequently than a short one. In the presence of diazepam $(D Z)(B)$ and phenobarbital $(P b B)(C)$, the distribution of channel open time was shifted to longer open times compared with $\gamma$-aminobutyric acid (GABA) alone (A). Frequency bistogram range is $1.0 \mathrm{msec}$ to $50.0 \mathrm{msec}$ and the binwidth is $0.5 \mathrm{msec}$. The number of openings contained in each bistogram were as follows: $G A B A=42,136 ; G A B A+D Z=12,976$; $G A B A+P b B=21,158$.

occurring together for more than $10 \mathrm{msec}$ would be counted as a burst.

GABA evoked bursts with a mean duration per application of $65.8 \pm 5.2 \mathrm{msec}$ (158 applications). In the presence of $\mathrm{DZ}$, mean $\mathrm{GABA}$ receptor burst duration was increased only by $9.3 \%$ ( $71.9 \pm 7.0 \mathrm{msec}, \mathrm{NS}, \mathrm{n}$ $=22$ ), but frequency of GABA-receptor bursts was increased by $102.5 \pm 6.5 \%(p<0.0001)$ (Fig 6). In contrast, in the presence of $\mathrm{PhB}$ mean GABA recep-

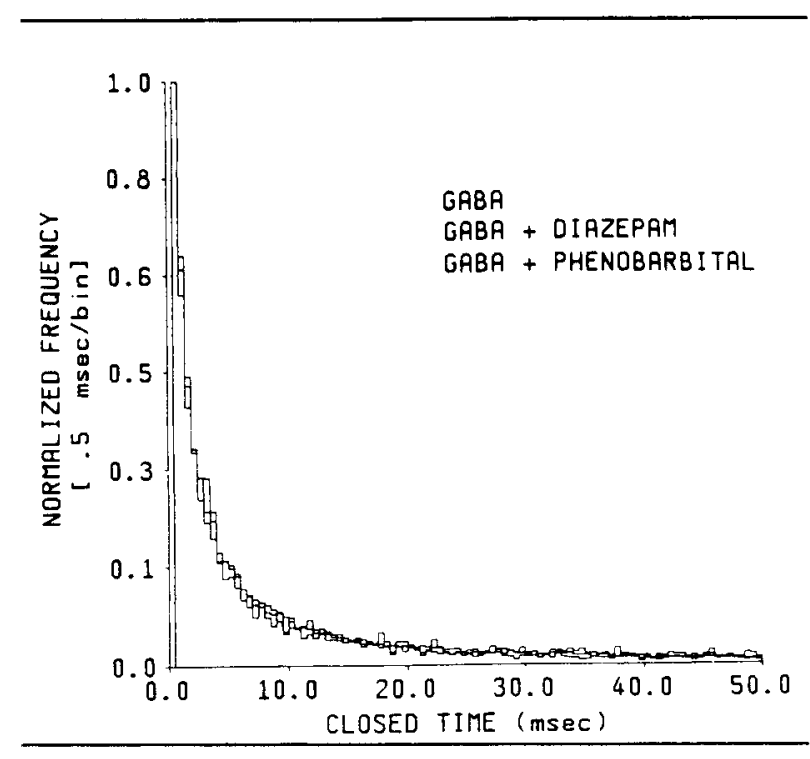

Fig 5. Normalized channel closed time frequency bistogram. Closed times varied over a wide range but are displayed only from 0.5 to $50.0 \mathrm{msec}$ with a $0.5 \mathrm{msec}$ binwidth. The distributions were overlapping for $\gamma$-aminobutyric acid alone and with diazepam and phenobarbital.

tor burst duration was prolonged by $81.9 \%(119.7 \pm$ $16.1 \mathrm{msec}, p<0.0001, \mathrm{n}=54$ ), but $\mathrm{GABA}$ receptor burst frequency increased only by $6.3 \pm 5.3 \%$ (NS) (see Fig 6). Thus, the mechanism of potentiation of GABA receptor current by $\mathrm{DZ}$ appeared to be mediated by increasing the likelihood or frequency of bursts evoked by GABA without altering the burst duration. $\mathrm{PhB}$, on the other hand, potentiated GABA receptor current by prolonging bursts without altering frequency. These burst properties indicate fundamentally different mechanisms of the regulation of GABA receptor chloride channel gating by $D Z$ and $\mathrm{PhB}$. 


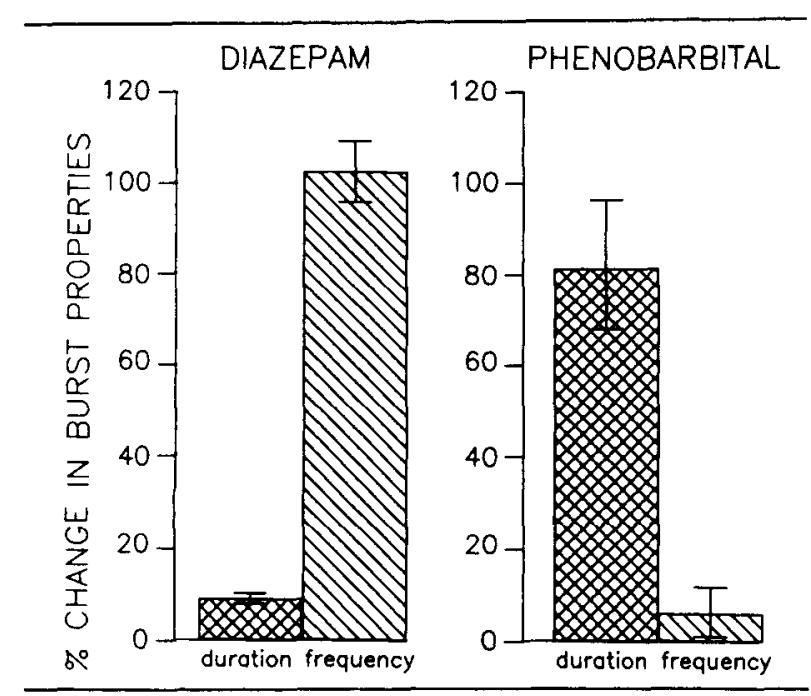

Fig 6. Diazepam and phenobarbital bad different effects on the properties of $\gamma$-aminobutyric acid $(G A B A)$-evoked bursts. Bursts are groups of openings that may represent times when a receptor is bound (see text for furtber explanation). The percent change from GABA alone in burst duration and burst frequency is shown for GABA-evoked bursts in diazepam and phenobarbital. In the presence of diazepam, GABA-evoked bursts were more frequent but were not prolonged. In contrast, in the presence of phenobarbital, burst frequency was not changed, but burst duration was prolonged.

\section{Discussion}

Patch clamp recording techniques have shown that GABA receptor single channel chloride currents are more complex than had been inferred from intracellular and noise analysis techniques $[14,15]$. GABA gates open chloride channels with multiple conductance states, but the 26- to $30-\mathrm{pS}$ state was the most frequent and contributed the majority of current used in this analysis [16]. At present, it is not clear whether the multiple conductance states represent different channels, but since the relative frequency of the states among patches remained relatively stable, it is likely that they represent different conformations of the same channel. In the present study, we showed that GABA receptor single channel currents were increased by $\mathrm{DZ}$ and $\mathrm{PhB}$. Since $\mathrm{DZ}$ and $\mathrm{PhB}$ did not alter the conductance of the dominant state, the enhancement of GABA receptor chloride current must have been due to an increase in the mean duration of channel opening or to an increased frequency of channel openings or to both.

The present study demonstrated that both $\mathrm{DZ}$ and $\mathrm{PhB}$ increased the mean open duration of single chloride channels evoked by GABA, but that $\mathrm{DZ}$ was more effective. Single channel opening frequency was not significantly altered. Since records that did not contain multiple channels were selected for analysis of single channel properties, the possibility of recruitment of additional channels as a means to achieve enhanced whole cell current was not evaluated in this study.

The single channel results contrast with those determined by noise analysis techniques. Using noise analysis techniques, Study and Barker [17] compared the effects of $\mathrm{DZ}$ and the effects of the anestheric barbiturate pentobarbital. DZ increased the "mean channel lifetime" in 12 of 18 cells, but an increase in frequency of channel opening was necessary to account fully for the increase in net current response. Pentobarbital increased "mean channel lifetime" to an extent greater than that necessary to account for the net current increase and was thus inferred to decrease the "channel opening frequency." The discrepancy between noise estimation and single channel results may be due to factors involving drug application and concentration and, more importantly, to the low resolution and limited frequency bandwidth of noise analysis techniques. Ligand concentrations generally used in single channel studies were lower than those used for intracellular and noise analysis techniques. The concentration of $\mathrm{DZ}$ used in the noise analysis study was 50 to 100 times that used in the present study. No comparable noise analysis study has been done to compare $\mathrm{DZ}$ and $\mathrm{PhB}$ actions on GABA currents, although Barker and McBurney [18] examined $\mathrm{PhB}$ alone at a high unknown concentration. They found that $\mathrm{PhB}$ increased GABA receptor "mean channel lifetime" to approximately five times that of control but did not comment on whether $\mathrm{PhB}$ altered the GABA receptor channel opening frequency. Macdonald and Barker [19] found that high concentrations of $\mathrm{PhB}$ evoked a moderate amount of chloride current directly, but at the concentration used in this study $(500 \mu \mathrm{M}) \mathrm{PhB}$ had little or no direct effect.

Noise analysis techniques may at times best resolve average currents with a duration of 5 to $10 \mathrm{msec}$. Since single channel recordings have shown that channel openings are brief and occur in complex bursts, it is likely that noise analysis techniques may resolve only bursts of openings. Studies of the ACh receptor channel have indicated that bursts of openings appear to be a fundamental response of binding of an agonist to a receptor-gated ion channel [9]. We examined GABAevoked burst properties in the presence of $\mathrm{DZ}$ and PhB. DZ did not prolong GABA-evoked bursts but increased their frequency. In contrast, GABA-evoked bursts in the presence of $\mathrm{PhB}$ were prolonged but were not increased in frequency. These burst properties were similar to those detected by noise analysis for "mean channel lifetime" and "channel opening frequency."

The difference between the single channel nonbursting properties (open time and opening frequency) 
and burst properties must be due to the way the channel openings were grouped to form bursts. Single channel studies of the concentration dependence of GABA receptor currents have demonstrated that increasing the concentration of GABA produces (1) an increase in channel opening frequency, (2) an increase in channel mean open duration by shifting the relative proportion of three types of open states to more stable long duration open states, and (3) a shift from isolated brief openings to bursts of long duration openings [20]. Burst prolongation was produced primarily by increasing a population of stable long-duration open states that were incorporated into bursts without altering burst structure or openings. A detailed kinetic analysis of this type is beyond the scope of the present paper; however, DZ appeared to enhance GABA receptor currents primarily by producing a relative shift in the open time population to long-duration states (see Fig 4) and by producing an increase in burst activity without altering bursts. These effects were similar to the effects of increasing GABA concentration.

The effect of $\mathrm{DZ}$ may be seen in a hypothetical series of channel openings evoked by GABA (Fig $7 A 1)$ and channel openings evoked by GABA in the presence of $\mathrm{DZ}$ (Fig 7A2). In this example, GABA evokes openings that occur in isolation and in groups (bursts, indicated by overbar). Openings occurring in bursts tend to be longer than those openings occurring in isolation. In the presence of $\mathrm{DZ}, \mathrm{GABA}$ receptor bursts increase in frequency and the bursts involve groups of long-duration openings that do not alter the burst duration. In a model for the modulation of bursting activity of the GABA receptor channel, the present results for $\mathrm{DZ}$ are consistent with action at the GABA binding site, where $\mathrm{DZ}$ is known to increase GABA binding affinity (Fig 7B). Brief, isolated openings that contribute little current are not represented in this model.

$\mathrm{PhB}$, on the other hand, did not produce an increase in the frequency of bursts but potentiated GABA currents primarily by prolongation of bursts. $\mathrm{PhB}$ also increased single channel open duration. Burst prolongation without an increase in burst frequency with $\mathrm{PhB}$ may have been accomplished by incorporating longer openings and additional openings each time GABA evoked a burst (Fig 7A3). This suggests an action beyond the GABA binding site, perhaps at or near the chloride channel (see Fig 7B). An increase in the number of openings per burst may be caused by a reduction of the likelihood of exiting a burst (intraburstclosed to extraburst-closed transition) or an increased likelihood of reopening once the channel has closed (intraburst closed to open transition) (see Fig 7B).

Thus, modulation of the main conductance state of GABA receptor by $\mathrm{DZ}$ and $\mathrm{PhB}$ was similar when the general properties of the single channel behavior was

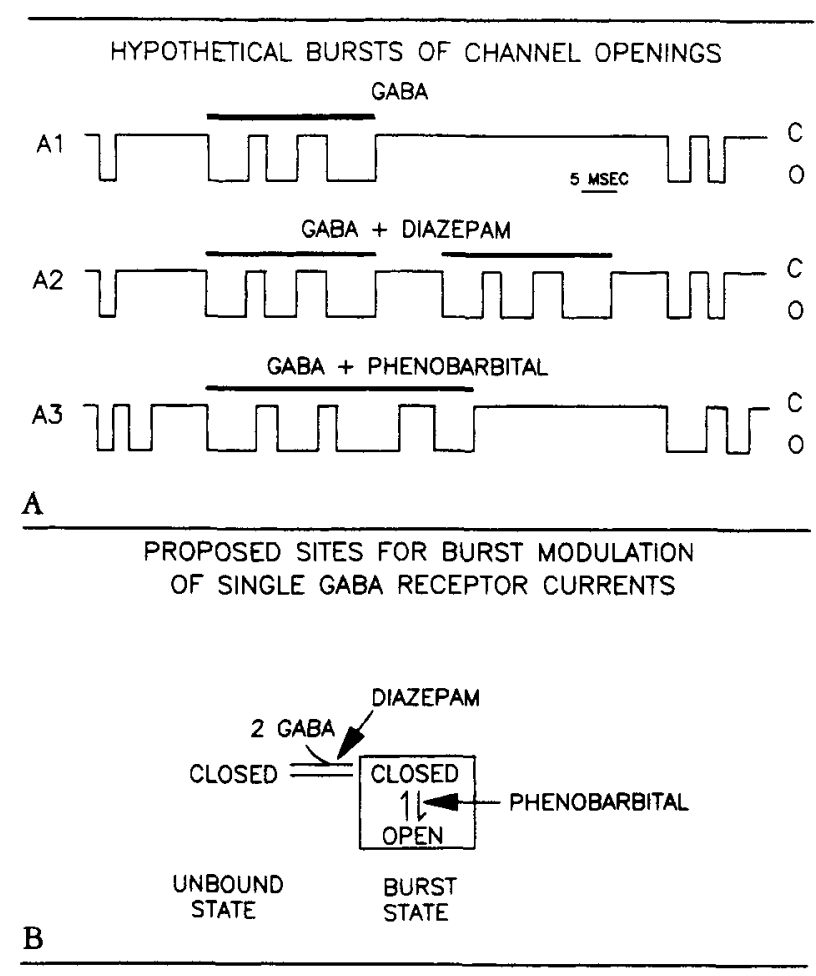

Fig 7. Hypotbetical bursting currents and sites of action for diazepam (DZ) and phenobarbital (PbB). (A1) $\gamma$-Aminobutyric acid (GABA) evoked frequent channel openings that occurred in isolation or in bursts. Bursts longer than 10 msec were overscored. (A2) In the presence of DZ, bursts with stable long openings were of the same duration and were more frequent, resulting in a shift in the open time distribution where longer openings were more frequent at the expense of brief isolated openings (see Fig 4). (A3) PbB prolonged bursts without increasing their frequency. This might bave resulted from bursts that were composed of prolonged and additional openings, since $P b B$ prolonged single channel openings (see Fig 4) and increased their frequency. $D Z$ and $P b B$ increased the percentage of time that the channel was opened by GABA and thereby increased the total chloride ion flux. (B) In a simplified burst kinetic model for the GABA receptor-cbloride channel complex, GABA (2 molecules) binds to gate open the chloride channel into bursts. Brief, isolated openings are not represented. $D Z$ enbanced $G A B A$ binding affinity to increased bursting activity witbout altering the $G A B A$ evoked burst. $P b B$ altered the $G A B A$-receptor burst by prolonging the time spent in an open state. The site of action may be at or near the channel to reduce the rate constant of channel closure.

examined. Only when the temporal characteristics of the channel were evaluated did details of differential regulation become apparent. It is possible that additional differences concerning burst modulation may be found by further evaluation of burst kinetics.

The patch clamp technique is a powerful method that allows investigation of physiological reactions between receptors and ion channels at a molecular level. Binding assays have demonstrated separate binding sites for $\mathrm{DZ}$ and $\mathrm{PhB}$ on the GABA receptor complex. The evidence presented here is the first to de- 
scribe at the single channel/receptor level two different modes of action for $\mathrm{DZ}$ and $\mathrm{PhB}$ and suggests that the unique drug binding sites have different regulatory functions at the GABA receptor chloride channel.

This work was supported by a US Public Health Service Grant Program project grant \# NS 022029 to Dr Macdonald. Dr Twyman was supported by an American Academy of Neurology neuropharmacology fellowship grant. Dr Rogers was supported by Department of Neurology training grant NS-07222.

We thank Ms Nancy Fox for her technical assistance in the preparation and maintenance of cell cultures and Ms Marjorie Mills for secretarial assistance.

\section{References}

1. Goodman LS, Gilman A, eds. The pharmacological basis of therapeutics. New York: Macmillan, 1980

2. Macdonald RL. Mechanisms of anticonvulsant drug action. In: Pedly TA, Meldrum B, eds. Recent advances in epilepsy. Vol I. Edinburgh: Churchill, 1983:1-23

3. Macdonald RL, Barker JL. Enhancement of GABA-mediated postsynaptic inhibition in cultured mammalian neurons: a common mode of anticonvulsant action. Brain Res 1979;367:323336

4. Macdonald RL, Skerritt JH, Werz MA. Barbiturate and benzodiazepine actions on mouse neurons in cell culture. In: Roth SH, Miller KW, eds. Molecular and cellular mechanisms of anesthesia. New York: Plenum Press 1985:17-25

5. Olsen RW. The GABA postsynaptic membrane receptoriontophore complex: site of action of convulsant and anticonvulsant drugs. Mol Cell Biochem 1981;39:261-279

6. Schofield PR, Darlison MG, Fujita N, et al. Sequence and functional expression of the $\mathrm{GABA}_{\mathrm{A}}$ receptor shows a ligand-gated receptor super-family. Nature 1987;328:221-227

7. Olsen RW. GABA-benzodiazepine-barbiturate receptor interactions. J Neurochem 1981;37:1-13
8. Sakmann B, Neher E, eds. Single channel recording. New York: Plenum Press, 1983

9. Colquhoun D, Sakmann B. Fast events in single-channel currents activated by acetylcholine and its analogues at the frog muscle end-plate. J Physiol (Lond) 1985;369:501-557

10. Ransom BR, Christian CN, Bullock PN, et al. Mouse spinal cord in cell culture: II. Synaptic activity and circuit behavior. J Neurophysiol 1977;40:1151-1162

11. Ransom BR, Bullock PN, Nelson PG. Mouse spinal cord in cell culture: III. Neuronal chemosensitivity and its relationship to synaptic activity. J Neurophysiol 1977;40:1163-1177

12. Ransom BR, Neale E, Henkart M, et al. Mouse spinal cord in cell culture: I. Morphology and intrinsic neuronal electrophysiologic properties. J Neurophysiol 1977;40:1132-1150

13. Macdonald RL. Neuropharmacology of spinal cord and dorsal root ganglion neurons in primary dissociated cell culture. In: Davidoff R, ed. Spinal cord pharmacology. New York: Dekker, 1983:381-408

14. Hamill OP, Bormann J, Sakmann B. Activation of multipleconductance state chloride channels in spinal neurons by glycine and GABA. Nature 1983;305:805-808

15. Hamill OP, Marty A, Neher E, et al. Improved patch clamp techniques for high-resolution current recording from cells and cell-free membrane patches. Pflugers Arch 1981;391:85-100

16. Bormann J, Hamill OP, Sakmann B. Mechanism of ion permeation through channels gated by glycine and $\gamma$-aminobutyric acid in mouse cultured spinal neurones. J Physiol 1987;385:243286

17. Study RE, Barker JL. Diazepam and (-)-pentobarbital: fluctuation analysis reveals different mechanisms for potentiation of $\gamma$ aminoburyric acid responses in cultured central neurons. Proc Natl Acad Sci USA 1981;78:7180-7184

18. Barker JL, McBurney RN. Phenobarbitone modulation of postsynaptic GABA receptor function on cultured mammalian neurons. Proc R Soc Lond 1979;B206:319-327

19. Macdonald RL, Barker JL. Anticonvulsant and anesthetic barbiturates: different postsynaptic actions in cultured mammalian neurons. Neurology 1979;29:432-447

20. Rogers CJ, Twyman RE, Macdonald RL. GABA-activated chloride currents have multiple kinetics. Soc Neurosci Abstr 1987;13:956 